\title{
Large Scale Experiments on the Investigation of the Effect of High Concentrations of Aflatoxin B1 on the Fermentation of Different Wines
}

\author{
Cs. Csutorás ${ }^{\mathbf{1}}$, K. Rácz ${ }^{2}$, G. Z. Nagy ${ }^{1}$, O. Hudák ${ }^{\mathbf{1}}$, L. Rácz ${ }^{\mathbf{1}}$ \\ ${ }^{1}$ Institute of Food Science, Egerfood Regional Knowledge Center, Eszterhazy Karoly University, Eger, Hungary \\ ${ }^{2}$ Eger Crown Winehouse Ltd., Kerecsend, Hungary \\ Email: "csuti@ektf.hu
}

Received December 2013

\begin{abstract}
The change of aflatoxin B1 (AFB1) content during must fermentation processes in different white, rosé and red musts was investigated, using selected yeast strains of Saccharomyces cerevisiae as starter cultures. Levels of AFB1 in must and lees were determined by high-performance liquid chromatography (HPLC) combined with diode array detection (DAD). Reductions of the AFB1 content between $\mathbf{7 7 \%}-\mathbf{9 7 \%}$ were recorded after 90 days must fermentations in the model systems, while the relative adsorption level of AFB1 in lees was around $\sim 0.63$ in case of white wines, $\sim 0.41$ in case of rosé wines and $\sim 0.23$ in case of red wines. The results show that even extremely high AFB1 levels do not affect the fermentation process and the life-circle of yeast strains. The concentration of AFB1 in wine can be controlled by using appropriate yeast strains during the alcoholic fermentation.
\end{abstract}

\section{Keywords}

Mycotoxicoses; Contamination; Decontamination; Food Safety; HPLC

\section{Introduction}

Aflatoxins produced by Aspergillus and Penicillum strains can be found mainly in cereals, cheese, peanuts, corn, almond, fruits and a wide group of other foods and feeds [1,2]. The main problem with these secondary metabolites is that they have mutagenic, toxic, carcinogenic and immunosuppressive effects on living organisms and we cannot destroy them easily, only by harsh heat-treatment [3]. Their production depends on environmental factors, such as temperature, humidity and other storage conditions [4,5]. Among 18 different types of aflatoxins, the B1 (AFB1) is the most widespread food contaminant [6,7].

Ochratoxin A (OTA) is a thoroughly investigated mycotoxin that is responsible mainly for toxin contaminations

\footnotetext{
"Corresponding author.
}

How to cite this paper: Csutorás, Cs., et al. (2014) Large Scale Experiments on the Investigation of the Effect of High Concentrations of Aflatoxin B1 on the Fermentation of Different Wines. Journal of Agricultural Chemistry and Environment, 3, 41-47. http://dx.doi.org/10.4236/jacen.2014.32B007 
of wines [8,9]. Grapes can be contaminated with a wide variety of moulds including Aspergillus and Penicillium genera. Among Aspergillus genus, black aspergilli seemed to be the most common contaminant of grapes namely Aspergillus niger aggregates and Aspergillus carbonarius the most known OTA-producing species. Reports by several authors showed that grape and its derived products such as dried vine fruits [10], grape juices and wines $[9,11,12]$ were highly contaminated by OTA.

However until now only a few number of publications deal with the possibility of contamination of wines with aflatoxins. There is a few available information on the occurrence of the AFB1 on grapes and its derived products since the studies conducted in Mediterranean countries revealed a very low occurrence of Aspergillus flavus in the vineyards [13-15]. However in these studies no quantification of AFB1 in grapes or its products was performed.

It is certain, that AFB1 can be produced by certain strains of the fungi Aspergillus flavus and Aspergillus parasiticus that are grown on grapes in the vineyards. These fungi can colonize and contaminate the grapes before grape-gathering and during storage, if water is allowed to exceed critical values for mould growth $[16,17]$. At grape-crushing they might contaminate the must thereby wines too. The minimal amount of the AFB1 allowed in plant foodstuffs is $2 \mu \mathrm{g} / \mathrm{kg}$. A thorough study would be important to reveal the real risk of AFB1 contamination of grapes and wines.

Different analytical methods are known for the determination of aflatoxins in a variety of matrices, like thin layer chromatography (TLC) [18,19], overpressure layer chromatography (OPLC) [20], high-pressure liquid chromatography (HPLC) [18,21], enzyme-linked immunosorbent assay (ELISA) [22] and optical waveguide lightmode spectroscopy (OWLS) [4].

Sripatomswat and Thasnakorn [18] were extracted fermented rice, soybean sauce, peanut butter, soy sauce, Thai red and white wine, and rice sugar wine and tested for aflatoxins by TLC and HPLC at $350 \mathrm{~nm}$. Adányi et al. [4] applied OWLS technique for the analysis of ochratoxins and aflatoxins in both competitive and direct immunoassays. The sensitive detection range of the competitive detection method was between 0.5 and 10 $\mathrm{ng} / \mathrm{mL}$. Rasch et al. [3] accomplished the qualitative and quantitative analysis of AFB1 in different wine and beer samples by one- and two-photon-induced fluorescence (OPIF and TPIF) techniques. The limit of detection were $31 \mathrm{ng} / \mathrm{mL}$ in white wine, $43 \mathrm{ng} / \mathrm{mL}$ in rose wine and $62 \mathrm{ng} / \mathrm{mL}$ in beer at $720 \mathrm{~nm}$, using OPIF. A better limit of detection can be achieved by TPIF, where the limit of detection at $360 \mathrm{~nm}$ wavelength were $6 \mathrm{ng} / \mathrm{mL}$ in white wine, $20 \mathrm{ng} / \mathrm{mL}$ in rose wine and $46 \mathrm{ng} / \mathrm{mL}$ in beer samples.

Previous studies showed that AFB1 can be detected in wines from southern regions, like Mediterranean vineyards [16], but the proofs of a real risk of aflatoxin contaminations in wines have not been enough yet. Further studies are necessary to be prepared for a possible aflatoxin contamination in grape and its derived products, like wines. Our previous study focused on the investigation of OTA during wine fermentation processes [23] and showed that the fermentation process and life-circle of the yeast strains were not affected even in the presence of extremely high levels of OTA.

The aim of our present work was to investigate the changes of AFB1 during the fermentation of red, white and rose wines that were artificially contaminated with different amounts of the mycotoxin. We focused in the paper on the investigation of the fermentation process, whether the fermentation is influenced or not in real must samples, that were inoculated with high concentrations of AFB1. Our experiments intended to build models for the effect of AFB1 contamination on the growth of yeast strains and to investigate the alterations of the levels of AFB1 during the fermentation process, to be able to estimate a possible risk of contamination. Thus previous studies carried out only micro-scale laboratory experiments, in this paper we focused on industrial scale investigations modelling real fermentation processes for the best.

\section{Materials and Methods}

\subsection{Reagents and Standards}

\subsubsection{Samples}

Red, rose and white wine musts were purchased from Eger Crown Winehouse Ltd., whose cellars were freely used for the experiments. Yeast strains of Saccharomyces cerevisiae type "Fermol Premier Cru" were purchased from AEB Biochemical Inc. (San Francisco, USA). 


\subsubsection{Reagents}

Solvents used for HPLC were ethanol 96\% of gradient grade for liquid chromatography and methanol, dichloromethane and acetonitrile for liquid chromatography, all purchased from Merck. In all analytical steps, deionized water generated by a Milli-Q P Ultra-Pure Water System from Millipore (Billerica, MA, USA) was used. Benzene-free AFB1 reference standard material was delivered by Sigma-Aldrich Chemical Ltd. (Schnelldorf, Germany).

\subsection{Method and Sample Preparation}

The stemmed, crushed and pressed red, rose and white wine musts were sulfurized (60 mg/L potassium- pyrosulfite) similarly to real wine making procedures. The musts were inoculated with yeast strains of Saccharomyces cerevisiae $(200 \mathrm{mg} / \mathrm{L})$. The inoculated musts were artificially contaminated with AFB1 at $0.5 ; 1.0 ; 2.0$; $4.0 \mu \mathrm{g} / \mathrm{mL}$ in triplicate, and stored in $16 \mathrm{~L}$ glass balloons in wine cellar at a permanent temperature of $12^{\circ} \mathrm{C}$. After 20 and 90 days samples were taken from the wines and after 90 days also from lees in order to determine the concentration of AFB1. HPLC analyses needed appropriate sample pre-treatment as follows: 8 mg sodium chloride was added to $100 \mathrm{~mL}$ must or lees sample then it was extracted with acetonitrile $(4 \times 30 \mathrm{~mL})$. The combined solutions were centrifuged for 5 minutes at 3800 rpm (Centrifuge 5810R, Eppendorf, Germany), then the clear solutions were evaporated by rotary evaporator (Laborota 4001, Heidolph, Germany). Before the HPLC measurements the samples were dissolved in $2 \mathrm{~mL}$ acetonitrile and filtered using a $0.2 \mu \mathrm{m}$ filter.

\subsection{Instrumentation for the Analysis of AFB1}

Analysis of AFB1: Quantitative analysis of must and wine samples has been carried out by a Shimadzu LCMS-2010EV instrument using a LC-20AB binary pump, SIL-20A sample changer, CTO-20A column oven and a SPD-M20A photodiode-array (PDA) detector. An Agilent Zorbax SB-C18 (4.6 × 250 mm, $5 \mu \mathrm{m})$ column was used for the chromatographic separations in an isochratic eluent setup with water/acetonitrile/methanol solvent system (3/1/1 ratio), the eluent flow rate was $1 \mathrm{~mL} / \mathrm{min}$ and $10 \mu \mathrm{L}$ sample was injected at the beginning of the chromatographic run. The signal of AFB1 was detected at $362 \mathrm{~nm}$ wavelength with a retention time of 18 min. 1 - $5 \mu \mathrm{g} / \mathrm{mL}$ standard AFB1 solutions were prepared and injected under the same experimental conditions and the signal integral values were used to calculate the linear calibration curve which was further used to calculate the AFB1 content of the wine and must samples. The following main analytical performance data were observed: linear range: 0.03 - $10 \mu \mathrm{g} / \mathrm{mL}$, recovery: 96\%, quantification limit: $0.02 \mu \mathrm{g} / \mathrm{mL}$, precision: \pm 0.01 $\mu \mathrm{g} / \mathrm{mL}$.

\section{Results and Discussion}

Our investigations focused on the experimental modelling of the change of AFB1 level during alcoholic fermentation of musts, applying a model system, which was similar to real conditions. Three different pre-treatments were applied of the must at the beginning of the experiments (selected yeast strains of Saccharomyces cerevisiae and sulfur were added in the first case, selected yeast strains of Saccharomyces cerevisiae but no sulfur were added to the must in the second case, and no additives were applied in the third part of experiments-in the latter case only wild yeasts can be worked). The results of the experiments are summarized in Table $\mathbf{1}$ and Table 2.

The most important observation of our investigations was that the fermentation process was not affected by the addition of high levels of AFB1. This means a potential risk in the case of the appearance of AFB1 producing mold species on grape, therefore our experiments appeal to researchers to study AFB1 in the wine product chain thoroughly in the near future. Our second observation is in correlation with our previous findings in the case of another mycotoxin, OTA [23]. As it can be seen from Table 1, the AFB1 contents in white, rose and red wines significantly decreased during the fermentation process in all concentration ranges. In white wines the concentration of AFB1 decreased after 90 days fermentation from 0.5 to $0.07 \mu \mathrm{g} / \mathrm{mL}$, from 1 to $0.16 \mu \mathrm{g} / \mathrm{mL}$, from 2 to 0.29 $\mu \mathrm{g} / \mathrm{mL}$ and from 4 to $0.55 \mu \mathrm{g} / \mathrm{mL}$. These findings imply a mean reduction percentage of $91 \%$ considering the initial concentrations. In rose wines the concentration of AFB1 decreased after 90 days fermentation from 0.5 to $0.05 \mu \mathrm{g} / \mathrm{mL}$, from 1 to $0.06 \mu \mathrm{g} / \mathrm{mL}$, from 2 to $0.07 \mu \mathrm{g} / \mathrm{mL}$ and from 4 to $0.14 \mu \mathrm{g} / \mathrm{mL}$, which means $95 \%$ reduction considering the initial concentrations.

In red wines the concentration of AFB1 decreased from 0.5 to $0.08 \mu \mathrm{g} / \mathrm{mL}$, from 1 to $0.08 \mu \mathrm{g} / \mathrm{mL}$, from 2 to 
Table 1. AFB1 level in musts during the fermentation process (Pre-treatment $1=$ yeast and sulfur added; $2=$ yeast but no sulfur added; 3 = no yeast and no sulfur added).

\begin{tabular}{|c|c|c|c|c|c|}
\hline \multirow[t]{2}{*}{ Wine } & \multirow[t]{2}{*}{ Pre-treatment method } & \multicolumn{3}{|c|}{$\mathrm{AFB}_{1}$ in wine and must during fermentation $(\mu \mathrm{g} / \mathrm{mL})$} & \multirow[t]{2}{*}{ Reduction rate } \\
\hline & & 0 day & 20 days & 90 days & \\
\hline chardonnay & 1 & 0.49 & 0.21 & 0.07 & $86 \%$ \\
\hline chardonnay & 2 & 0.48 & 0.24 & 0.08 & $84 \%$ \\
\hline chardonnay & 3 & 0.47 & 0.21 & 0.09 & $82 \%$ \\
\hline chardonnay & 1 & 1.01 & 0.48 & 0.16 & $84 \%$ \\
\hline chardonnay & 2 & 0.96 & 0.34 & 0.22 & $78 \%$ \\
\hline chardonnay & 3 & 0.95 & 0.31 & 0.23 & $77 \%$ \\
\hline chardonnay & 1 & 1.93 & 0.90 & 0.26 & $87 \%$ \\
\hline chardonnay & 2 & 1.92 & 0.46 & 0.29 & $86 \%$ \\
\hline chardonnay & 3 & 1.91 & 0.45 & 0.31 & $85 \%$ \\
\hline chardonnay & 1 & 3.85 & 1.91 & 0.65 & $84 \%$ \\
\hline chardonnay & 2 & 3.86 & 0.95 & 0.60 & $85 \%$ \\
\hline chardonnay & 3 & 3.84 & 0.68 & 0.55 & $86 \%$ \\
\hline bluefrank rose & 1 & 0.48 & 0.09 & 0.05 & $90 \%$ \\
\hline bluefrank rose & 1 & 0.95 & 0.14 & 0.06 & $94 \%$ \\
\hline bluefrank rose & 1 & 1.90 & 0.30 & 0.07 & $97 \%$ \\
\hline bluefrank rose & 1 & 3.82 & 0.59 & 0.14 & $97 \%$ \\
\hline cabernet sauvignon & 1 & 0.47 & 0.15 & 0.08 & $84 \%$ \\
\hline cabernet sauvignon & 1 & 0.97 & 0.26 & 0.08 & $96 \%$ \\
\hline cabernet sauvignon & 1 & 1.94 & 0.44 & 0.21 & $90 \%$ \\
\hline cabernet sauvignon & 1 & 3.88 & 0.76 & 0.18 & $96 \%$ \\
\hline
\end{tabular}

"Reduction rate (\%): 100-(100× Measured concentration of AFB1 in wine after 90 days /Added amount of AFB1).

Table 2. $\mathrm{AFB}_{1}$ level in lees at the end of the fermentation process (Pre-treatment 1 = yeast and sulfur added; $2=$ yeast but no sulfur added; 3 = no yeast and no sulfur added).

\begin{tabular}{cccc}
\hline Wine & Pre-treatment method & AFB1 in lees after fermentation $(\mu \mathrm{g} / \mathrm{mL})$ & Relative adsorption values $^{*}$ \\
\hline chardonnay & 1 & 0.29 & 0.59 \\
chardonnay & 2 & 0.16 & 0.33 \\
chardonnay & 3 & 0.26 & 0.51 \\
chardonnay & 1 & 0.38 & 0.38 \\
chardonnay & 2 & 0.85 & 0.74 \\
chardonnay & 3 & 0.74 & 0.69 \\
chardonnay & 1 & 1.37 & 0.61 \\
chardonnay & 2 & 1.21 & 0.37 \\
chardonnay & 3 & 0.74 & 0.69 \\
chardonnay & 1 & 2.75 & 0.53 \\
chardonnay & 2 & 2.10 & 0.60 \\
chardonnay & 3 & 2.41 & 0.52 \\
bluefrank rose & 1 & 0.26 & 0.42 \\
bluefrank rose & 1 & 0.42 & 0.21 \\
bluefrank rose & 1 & 0.42 & 0.50 \\
bluefrank rose & 1 & 2.00 & 0.24 \\
cabernet sauvignon & 1 & 0.12 & 0.18 \\
cabernet sauvignon & 1 & 0.18 & 0.22 \\
cabernet sauvignon & 1 & 0.44 & 0.26 \\
cabernet sauvignon & 1 & 1.03 & \\
\hline
\end{tabular}

*Relative adsorption: Measured concentration of AFB1 in lees/Added amount of AFB1. 
$0.21 \mu \mathrm{g} / \mathrm{mL}$ and from 4 to $0.18 \mu \mathrm{g} / \mathrm{mL}$ after 90 days of fermentation, which means $90 \%$ reduction ratio. The pre-treatment procedures had no effect on the overall decrease of the AFB1 content of the samples. Even in the absence of added starter yeasts the natural yeast cultures of the grape and cellar could start the fermentation process and therefore no significant differences were observed in the reduction percentages. The greatest reduction of AFB1 concentration in the must was achieved in the case of rose wine (95\%), followed by white wine (91\%). On the other hand red wine showed the lowest AFB1 reduction rates with an average reduction percentage of 90. This value represents still a significant reduction rate of AFB1 level during fermentation. Experiments were also done on a different way, whose results are not indicated in Table 1. In these experiments musts were sulfurized and no yeasts were applied. In this case the fermentation of wine was not started, that can be explained with the destroying effect of sulfur on the natural yeast species of musts. These experiments were finished after 20 days, because the fermentation process did not start. But the results were surprising because no change of AFB1 levels were obtained. These findings indicate that the mechanism of the reduction of AFB1 concentrations in musts should be similar to the supposed mechanism for OTA which was thoroughly investigated in contrast with AFB1 [23-25]. The mechanism involved physical adsorption process by the cell-walls of the microorganisms similarly to other mycotoxins [26].

The results that are summarized in Table 2 harmonize with the literature data, namely mycotoxins were accumulated in lees. The chemistry and the molecular basis of mycotoxin binding was previously thoroughly examined, according to the present knowledge from literature data the reduction mechanism may consist of physical binding of the toxin to the cell wall proteins of the applied yeast [27,28]. According to our experimental data a similar model can be supposed for the explanation of the reduction of AFB1 level during wine fermentation processes, namely a physical adsorption of the toxin to the yeast cells can be occurred to obtain significant reduction of its concentration in must. We can conclude that a natural clarification process occurs during wine fermentation process which results in an average $90 \%$ reduction of mycotoxin concentration during the ripening process.

\section{Conclusion}

Saccharomyces cerevisiae, the most important yeast strain involved in wineries, can reduce AFB1 level in wine must during the fermentation process even by $77 \%$ - 97\%. The reduction rate changed depending on the variety of must, but no significant differences were observed in AFB1 removal with regard to the initial AFB1 concentrations. The experiments which were carried out without adding starter yeasts after sulfurization delivered indirect evidences about the mechanism of the reduction of the AFB1 level. According to our results we can suppose that the reduction can be connected to the yeast cells, presumably to an adsorption process. In the developed model system we used AFB1 in extremely high concentrations to investigate the toxin's effect on yeast cells and on changes of the amount of toxin during the fermentation. These changes can be extrapolated onto lower AFB1 concentrations according to our previous findings in the case of OTA [23]. The results of our experiments demonstrated that even at a contamination level of $10 \mu \mathrm{g} / \mathrm{L}$, the AFB1 concentration can be reduced under $2 \mu \mathrm{g} / \mathrm{L}$, which is the European limit value for AFB1 in alcoholic beverages.

\section{Acknowledgements}

This work was supported by a GOP-1.3.1. project of New Szechenyi Plan, titled "Elaboration of an efficient wine technology for the elimination of mycotoxins".

\section{References}

[1] Czerwiecki, L., Wilczynska, G. and Kwiecien, A. (2006) Mycotoxins in Several Polish Food Products in 2004-2005. Mycotoxin Research, 22, 159-162. http://dx.doi.org/10.1007/BF02959269

[2] Moss, M.O. (1989) Mycotoxins of Aspergillus and Other Filamentous Fungi. Journal of Applied Bacteriology Symposium Supplement, 67, 69-81. http://dx.doi.org/10.1111/j.1365-2672.1989.tb03771.x

[3] Rasch, C., Böttcher, M. and Kumke, M. (2010) Determination of Aflatoxin B1 in Alcoholic Beverages: Comparison of One and Two-Photon-Induced Fluorescence. Analytical and Bioanalytical Chemistry, 397, 87-92. http://dx.doi.org/10.1007/s00216-010-3530-1

[4] Adányi, N., Levkovets, I.A., Rodriguez-Gil, S., Ronald, A., Váradi, M. and Szendrő, I. (2007) Development of Immunosensor Based on OWLS Technique for Determining Aflatoxin B1 and Ochratoxin A. Biosensors and Bioelectronics, 22, 797-802. http://dx.doi.org/10.1016/j.bios.2006.02.015 
[5] Ramos, A. J., Labernia, N., Marin, S., Sanchis, V. and Magan, N. (1998) Effect of Water Activity and Temperature on Growth and Ochratoxin Production by Three Strains of Aspergillus ochraceus on a Barley Extract Medium and on Barley Grains. International Journal of Food Microbiology, 44, 133-140. http://dx.doi.org/10.1016/S0168-1605(98)00131-7

[6] Cervino, C., Knopp, D., Weller, M.G. and Niessner, R. (2007) Novel Aflatoxin Derivatives and Protein Conjugates. Molecules, 12, 641-653. http://dx.doi.org/10.3390/12030641

[7] Yu, J., Cleveland, T.E., Nierman, W.C. and Bennett, J.W. (2005) Aspergillus flavus Genomics: Gateway to Human and Animal Health, Food Safety, and Corp Resistance to Diseases. Revista Iberoamericana Micologica, 22, $194-202$. http://dx.doi.org/10.1016/S1130-1406(05)70043-7

[8] Spadaro, D., Loré, A., Garibaldi, A. and Gullino, M.L. (2010) Occurrence of Ochratoxin A before Bottling in DOC and DOCG Wines Produced in Piedmont (Northern Italy). Food Control, 21, 1294-1297. http://dx.doi.org/10.1016/j.foodcont.2010.02.017

[9] Zimmerli, B. and Dick, R. (1996) Ochratoxin A in Table Wine and Grape Juice: Occurrence and Risk Assessment. Food Additives and Contaminants, 13, 655-668. http://dx.doi.org/10.1080/02652039609374451

[10] MacDonald, S., Wilson, P., Barmes, K., Damant, A., Massey, R., Mortby, E. and Shepherd, M.J. (1999) Ochratoxin A in Dried Fruit: Method Development and Survey. Food Additives and Contaminants, 16, 253-260. http://dx.doi.org/10.1080/026520399284019

[11] Otteneder, H. and Majerus, P. (2000) Occurrence of Ochratoxin A in Wines: Influence of the Type of Wine and Its Geographical Origin. Food Additives and Contaminants, 17, 793-798. http://dx.doi.org/10.1080/026520300415345

[12] Visconti, A., Pascale, M. and Centonze, G. (1999) Determination of Ochratoxin A in Wine by Means of Immunoaffinity Column Clean-Up and High-Performance Liquid Chromatography. Journal of Chromatography, 864, 89-101. http://dx.doi.org/10.1016/S0021-9673(99)00996-6

[13] Martinez-Culebras, P.V. and Ramon, D. (2007) An ITS-RFLP Method to Identify Black Aspergillus Isolates Responsible for OTA Contamination in Grapes and Wine. International Journal of Food Microbiology, 2, 147-153. http://dx.doi.org/10.1016/j.ijfoodmicro.2006.06.023

[14] Medina, A., Mateo, R., Lopez-Ocana, L., Valle-Algarra, F.M. and Jimenez, M. (2005) Study of Spanish Grape Mycobiota and ochratoxin A Production by Isolates of Aspergillus tubingensis and Other Members of Aspergillus Section Nigri. Applied Environmental Microbiology, 71, 4696-4702. http://dx.doi.org/10.1128/AEM.71.8.4696-4702.2005

[15] Melki Ben Fredj, S., Chebil, S., Lebrihi, A., Ghorbel, A. and Mliki, A. (2007) Occurrence of Pathogenic Fungal Species in Tunisian Vineyards. International Journal of Food Microbiology, 3, 245-250. http://dx.doi.org/10.1016/j.ijfoodmicro.2006.07.022

[16] Khoury, A.E.L., Rizk, T., Lteif, R., Azoury, H., Delia, M.L. and Lebrihi, A. (2008) Fungal Contamination and Aflatoxin B1 and Ochratoxin A in Lebanese Wine-Grapes and Musts. Food Chemical Toxicology, 6, 2244-2250. http://dx.doi.org/10.1016/j.fct.2008.02.026

[17] Pietri, A., Rastelli, S. and Bertuzzi, T. (2010) Ochratoxin A and Aflatoxins in Liquorice Products. Toxins, 2, 758-770. http://dx.doi.org/10.3390/toxins2040758

[18] Sripatomswat, N. and Thasnakorn, P. (1981) Survey of Aflatoxin-Producing Fungi in Certain Fermented Foods and Beverages in Thailand. Mycopathologia, 73, 83-88. http://dx.doi.org/10.1007/BF00562595

[19] Var, I., Kabak, B. and Gök, F. (2007) Survey of Aflatoxin B1 in Helva, a Traditional Turkish Food, by TLC. Food Control, 18, 59-62. http://dx.doi.org/10.1016/j.foodcont.2005.08.008

[20] Móricz, Á.M., Fáter, Zs., Otta, K.H., Tyihák, E. and Mincsovics, E. (2007) Overpressured Layer Chromatographic Determination of Aflatoxin B1, B2, G1 and G2 in Red Paprika. Microchemical Journal, 85, 140-144. http://dx.doi.org/10.1016/j.microc.2006.03.007

[21] Calleri, E., Marrubini, G., Brusotti, G., Massolini, G. and Caccialanza, G. (2007) Development and Integration of an Immunoaffinity Monolithic Disk for the On-Line Solid-Phase Extraction and HPLC Determination with Fluorescence Detection of Aflatoxin B1 in Aqueous Solutions. Journal of Pharmaceutical and Biomedical Analysis, 44, 396-403. http://dx.doi.org/10.1016/j.jpba.2007.01.030

[22] Pei, S.C., Zhang, Y.Y., Eremin, S.A. and Lee, W.J. (2009) Detection of Aflatoxin B1 in Milk Products from China by ELISA Using Monoclonal Antibodies. Food Control, 20, 1080-1085. http://dx.doi.org/10.1016/j.foodcont.2009.02.004

[23] Csutorás, C., Rácz, L., Rácz, K., Fűtő, P., Forgó, P. and Kiss, A. (2013) Monitoring of Ochratoxin A during the Fermentation of Different Wines by Applying High Toxin Concentrations. Microchemical Journal, 107, 182-184. http://dx.doi.org/10.1016/j.microc.2012.07.001

[24] Bejaoui, H., Mathieu, F., Taillandier, P. and Lebrihi, A. (2004) Ochratoxin A Removal in Synthetic Medium and Natural Grape Juices by Selected Oenological Saccharomyces Strains. Journal of Applied Microbiology, 97, 1038-1044. http://dx.doi.org/10.1111/j.1365-2672.2004.02385.x 
[25] Meca, G., Blaiotta, G. and Ritieni, A. (2010) Reduction of Ochratoxin A during the Fermentation of Italian Red Wine Moscato. Food Control, 21, 579-583. http://dx.doi.org/10.1016/j.foodcont.2009.08.008

[26] Bueno, D.J., Casale, C.H., Pizzolitto, R.P., Salvano, M.A. and Oliver, G. (2007) Physical Adsorption of Aflatoxin B1 by Lactic Acid Bacteria and Saccharomyces cerevisiae: A Theoretical Model. Journal of Food Protection, 70, 21482154.

[27] Devegowda, G., Raju, M.V.L.N. and Swamy, H.V.L.N. (1998) Mycotoxins: Novel Solutions for Their Counteraction. Feedstuffs, 70, 12-15.

[28] Ringot, D., Lerzy, B., Bonhoure, J.P., Auclair, E., Oriol, E. and Larondelle, Y. (2005) Effect of Temperature on in Vitro Ochratoxin A Biosorption onto Yeast Cell Derivatives. Process Biochemistry, 40, 3008-3016.

http://dx.doi.org/10.1016/j.procbio.2005.02.006 